\title{
Research on the Application of Video Resources in Conspectus Teaching
}

\author{
HuangJing \\ Yunnan Police Officer Academy, Kunming650223, China. \\ huangjing78820@163.com
}

Keywords: Conspectus; teaching; video resources

\begin{abstract}
With the development of media technology, we are stepping into a "Screen-reading era". The appearance of Massive open online course (MOOC for short) and Inverted Classroom makes video "reinvent education" all the time. A means of knowledge transfer mode of education based on video starts to have increasing impact on the college classes. Using video resource in Conspectus teaching can promote students' interest and efficiency of study; it has been the conscious pursuit of vast majority teachers teaching this course. Apart from this, it is also of great significance for us to study the course phenomenon from the aspect of theory and practice to understand which video resources can be used to the practical education, which principle should we follow, which strategy can be used and so on. All of these can help us to use the video resources in the Conspectus teaching scientific, rational and effective.
\end{abstract}

\section{INTRODUCTION}

With the advances in media and audiovisual technology, we have stepped into a period of rapid development of film and television production, circulation and consumption. As Heidegger said, it is enter a "world image era", in this era, "the world has been grasped as image". It has a very import characterization is what has happened on the philosophical significance of visual culture shift: "from the culture centered of language to the culture centered of image", "in the significance of comparison, we are increasingly dominated by visual media, our values, opinions and beliefs affected by the powerful influence of visual culture more and more obviously". However, Conspectus is an Ideological and Political curriculum, there is an interaction presenting among history teaching, "image era" and the representative technology of this era. Traditionally, we know and teach the history all depend on the oral teaching and text reading and now has been changed into film and video watching. This phenomenon is resulted from problems, requirements and probe develop direction of the "image era" and visual culture.Overall, the application of video resources is promoting a new revolution in the history teaching and is becoming an important means of Conspectus teaching.

\section{SIGNIFICANCE OF APPLICATION OF VIDEO RESOURCES IN CONSPECTUS TEACHING}

Nowadays, more and more video resources have been used in Conspectus teaching, it has multiple meanings reflecting in three aspects, firstly is making the teaching content has a vivid presentation; then is the rich teaching method; and then is it have changed the traditional history learning way. So, for the history teaching, the using of video resources has incalculable significance.

\section{It Can Make the History Come Alive and Visible}

As Balazs ever had said, "Television makes the buried concept and people in the text re-see the sun and makes the people visible". Through the video resources, not only can we see the historical characters' facial expression, gestures and the historical character's inner world also becomes "visible". Changes video resources bring to the history teaching are like the American Historian Lake said, "Written historiography fully reflect the complex of the human life, how monotonous and poor the multi-dimensional world is. Only by dubbing the film, lens switching and some other 
techniques is able to close to the real life, such as ideas, words, images, conscious or unconscious motivation and emotion we experience every day, only by these can we have a much better understanding about the historical figures and the historical events. Only the film can provide adequate 'empathy reconstruction' to transfer how historical characters witness, understand and live. And only film can help historians make the past lifelike and vivid" Especially for those major historical events, video resources can bring the leaners into the "real" situation. Through the movie language of close-up, scene scheduling, montage, we can obtain a new psychological effects, the psychological effect is the unity of the audience and the characters in the movie. This can enable learners to produce immersive feeling, as if personally involved in the events that occurred in history, furthermore, it also can help the learners obtain more real feelings about the history events. Only when the students have the feeling of involved in the event can they understand the practical meaning of the teaching section, apart from this, they can also realize the influence these events have on the country, the people and the society.

\section{It Can Develop the Students' Historical Thinking Ability}

Historical thinking includes both abstract, literal of thinking and figure, image of thinking. But for a long time, we only pay attention to the literal thinking and ignore the image thinking in Ideological and Political curriculum teaching. Gestalt psychology school found that people's vision is a multiple intelligence and an ability to accurate to observe and explain the world. Psychologist Arnheim proposed a concept of "visual thinking", he believes that human's vision also have the same understanding and rational thinking ability, that is to say, people can understand the outside world visually, he said "consciousness live in the level of feeling can also achieve the thing called 'understanding' in the field of rational thinking. Anyone's eyesight can demonstrate an artist who has an enviable ability in a simple way. This is the kind of way through the organization create the schema capability to reveal the experience effectively."'The process of video watching is completed by the participation of language, thought and image in the same time, from this we can find it is unnecessary for these researchers to think that use the video resources in history teaching may lead inertia in students' thinking and understanding.

\section{It Can Promote Change in the Way of Students Learning}

The application of video resources in Conspectus teachingwill must result in change of study way, this audiovisual learning will also enhance the learning efficiency. The study group administrated by Mcluhan ever had done a learning experiment; they divided the students into four experimental groups, and specify each group contact only one spread pipe. During the experiment, each group get a same lecture at the same time but through a different way. One group read directly, one group stayed in a studio and as a formal lecture to listen, one group listened to the radio, and the last one both listened and watched on television. Soon after that, all of them were given a test to determine how much about the new and difficult material did these students grasped. As a result, the group watching TV is the best, then is the group listening to the radio, followed by the group is the one stay in the studio, reading group is the last one. Overall, this experiment is of great significance for us to analyze the using of video resources in history teaching.

\section{PRINCIPLE OF APPLICATION OF VIDEO RESOURCES IN CONSPECTUS TEACHING}

As mentioned before, several problems exist in the process of the using of video resources in college Ideological and Political curriculum teaching, such as:firstly, some teachers use too much video resources in the classroom, this has flooded the proper teaching and miss to explore and explain some important teaching content; secondly, some teachers analysis the video resources not very sufficient, and failed to carry out deep-level mining, so the content is lack of depth, the video resources'value is not fully utilized; Last but not least, Without a proper selection, the film used lacking of history teaching pertinence. To overcome these problems, we must put forward some basic principles clearly, and follow these principles absolutely, then draw a clear boundary in order to overcome teachers' arbitrariness during the process of the use of video resources. Apart from this, it can improve the effectiveness of the using of video resources and complete the teaching objective much better. 


\section{Authenticity Principle}

Authenticity principle is proposed target at the problems exist in the process of video resources selection. Authenticity of film work includestruth of history and truth ofhistorical spirit. The meaning of the truth of history is extremely complex, both real behavior, emotion and inner, external reality. If only regard the truth of history as a faithful reflection of the outside world, it will bring prejudice, unilateral and false to the truth of history. The reality of behavior and external can be regarded as the reality of the real history spirit. In the film and television works, the reality of the historical spirit is more important than the reality of the history itself, and is the essence of true history. The authenticity of film history is not in accordance with external, intuitive and shallow sense of the historical fact, but it is in keeping with the internal, speculative and deep sense of history nature. To describe the truth of history, film and television works only pursuit the truth of historical spirit and essence. So in these works, the history is only consistent with the historical spirit, and neither possibly nor necessary consistent with the objective of history. This is an important criterion for us to judge the authenticity of video resources. Historical documentaries, historical image is in the field and real situation freeze of the real history. So it is no doubt to apply the video history to the history teaching.

\section{Limitation Principle}

Limitation principle is proposed target at the problems of abusing video resources in the process of history teaching. It requires teachers shouldrecognize the limitation of video resources' function, and it can't entirely replace teachers' teaching, furthermore, students' thinking, discussing and exchange can't be replaced either. When we use the video resources, we must keep a proper time length and proper amount.

\section{Effectiveness Principle}

Effectiveness principle is proposed target at the problems exist in the process of using the video resources to analysis, mining, especially to accomplish the teaching objective. During this process, video resources must service for the teaching objectives, and closely linked to the teaching objectives, highlight the core and concept of teaching, can't engage in formalism. To judge video resources whether have influence on Conspectus teaching or not, we must have a clear criterion. These criterions come from two aspects, the one is the standard of Conspectus teaching, and the other is our analysis of the using function and purpose about video resources. The combination of these two aspects is the goal we want to achieve during the process of using video resources.

\section{STRATEGY OF APPLICATION OF VIDEO RESOURCES IN CONSPECTUS OF CHINESE MODERN HISTORY TEACHING}

In Conspectus teaching, video resources can greatly enrich the presentation of teaching content, also change the traditional teaching method of teach and explain the knowledge in book only.

\section{Using Video Resources to Create Historical Context}

History teaching should give students a real experience and feeling, and it is of great significance to create a rational historical context during teaching process. The historical context created should combine the real problem situation and link with the real life and the people live in different history situation, so as to enable students gain the real experience and feeling about the history. Because of its unique habitability, visibility and intuitive, so the video resources are very suitable for the creation of historical context. For example, before describe some historical events and understand some historical characters, we can broadcast some relative video resources. This can attract students quickly and take students into the very historical situation. After entering the situation, it is much easier for students to get the deep feeling and thinking about the history. And then teachers guide students to discuss surrounding the core, by this you can get unexpected results. During the discussion, students can get their own conclusion, and then the depth and the flexibility of historical thinking will be promoted. To the practical significance of historical event, while students' watching of video resources, they put themselves into it, and 'undergo' the event all by themselves. So, during the teaching, students can also get their own feeling, and have a much deeper understand about the historical event. 


\section{Explore Historical Issues by Retrieving Historical Film}

The purpose of history teaching is to teach students to explore history, discover the historical truth all by themselves. Exploration begins with question, and students' study often starts from openness, so a good question is very significant. A good question can activate students' curiosity and thirsty for knowledge, and enable them to explore and discover the knowledge in the way they like. Using this method, students will inevitably exposed to a large quantity of video material and submerge in it. If without the guidance of teachers, it will lack of deep thinking, criticism, so the proper teaching effect would not be achieved. To this end, teachers should timely remind students to keep in mind what the watching purpose is and what problems should they take into consideration during the process of watching. By this, students will have a definite object in view and think problems while watching, apart from these, in the long run, their consciousness about problem will be formed and the interests about historical issues will be activated.

\section{Apply Video Resources to Confirm the Text and Solve the Difficulty in Teaching}

Due to the reason of age and experience, college students have some difficulty in understanding some complex historical knowledge. Therefore, teachers can let students have a deep reading of teaching material, based on this, supplement some historical material viewing can help students to understand some ancient and hard historical knowledge. Meanwhile, use the video resources to confirm students' understanding about the historical knowledge.Apart from this, using this approach also can help students understand the obscure historical problems in a visualized and contextualized way.

\section{CONCLUSION}

Application of video resources in Conspectus teaching is the production of the development of media technology. Under the background of culture, it is also a necessary requirement for college students' learning habits. Video resources enter the Conspectushave changed the traditional way of history teaching. With its application, students' historical thinking can be formed; history learning interest can be promoted.

\section{REFERENCES}

[1] Walter, Benjamin, and Hannah Arendt. Illuminations: Essays and Reflections. Berlin: Schocken Books, 1969.

[2] Andrew Lynn Appreciating Cinema[M].Beijing Foreign Language Teaching and Research Press, 2005.

[3] MassiM A G Merino Film and EFL in English Teaching[J].Forum1996.

[4] A.K. Dicklnson, P.J. Lee and P.T Roger.Learning History[M]. London, 1984, 169.

[5] Counsell, Christine, Teaching History, (History Today, Nov. 1999). 